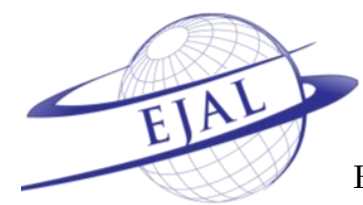

Eurasian Journal of Applied Linguistics 3(2) (2017) 325-347
Available online at www.ejal.eu

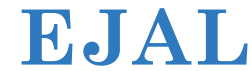

Eurasian Journal of Applied Linguistics

\title{
Synectics as a prewriting technique: Its effects on writing fluency and lexical complexity
}

\author{
Nalan Bayraktar Balkır a * (D), Ece Zehir Topkaya a \\ ${ }^{a}$ Çanakkale Onsekiz Mart University, Çanakkale, 17020, Turkey
}

Received 10 August 2017 | Received in revised form 24 August 2017 | Accepted 30 August 2017

\begin{abstract}
This study aimed to explore the effects of synectics as a prewriting technique on writing fluency and lexical complexity in the written texts of 20 tertiary level Turkish EFL learners. To this end, a mixed research design was adopted combining both quantitative and qualitative techniques. Repeated measures design was employed to examine the differences in participants' writing fluency and lexical complexity over time, and to gain a deeper understanding of learners' experiences, semi-structured interviews were conducted. The learner-written texts were analyzed using VocabProfile (VP), an online text analysis program, with respect to fluency and lexical complexity. Descriptive statistics, Friedman test for repeated measures, and Wilcoxon Signed Ranks test were carried out as data analysis procedures. As for the analysis of the qualitative data, inductive content analysis was performed. The findings revealed that the participants' writing fluency increased significantly at the end of the program. On the other hand, their lexical complexity remained the same during the study. In terms of the results of the qualitative analysis, the participants had mostly positive perceptions about their synectics experience in terms of vocabulary learning, improvement of writing skills, and attitudes to writing.
\end{abstract}

(C) 2017 EJAL \& the Authors. Published by Eurasian Journal of Applied Linguistics (EJAL). This is an open-access article distributed under the terms and conditions of the Creative Commons Attribution license (CC BY-NC-ND) (http://creativecommons.org/licenses/by-nc-nd/4.0/).

Keywords: Attitudes to writing; lexical complexity; prewriting techniques; synectics; writing fluency.

\section{Introduction}

Although writing is an important component of communication, its instruction in foreign language education (henceforth FLE) has not received as much attention as it deserved, especially with a comparison to the teaching of other language areas or skills. In addition, the features of product approach to writing still appear to dominate the writing instruction in many FLE contexts. The common second language (henceforth L2) writing instruction generally reflects the features of controlled composition model whereby learners are directed to practice grammatical patterns through guided writing activities. On the other hand, with the effect of process approach derived from experiential philosophy (Nunan, 1999), language learners have

\footnotetext{
* Nalan Bayraktar Balkır.

E-mail address: bayraktar6@yahoo.com

http://dx.doi.org/.
} 
started to be considered as writers and creators of texts which are products of highly complex cognitive processes (Raimes, 1991). As a result, the process of creating of a text has come to the foreground in L2 writing instruction, which led to an increase in the amount of research investigating various dimensions and stages of this process (see for example Açıkgöz Karakaş, 2011; Diaw, 2009; Hashempour, Rostampour \& Behjat, 2015).

Of the studies implemented, it can be seen that a variety of prewriting techniques have also been examined. Most studies focused on the effects of such techniques on learner related factors like motivation, attitudes, interest, awareness, self-discovery, etc. (e.g. Diaw, 2009; Özbek, 2006); and few explored their effects on writing skills or improvement in writing rhetorical modes (e.g. Öncü, 1999; Özçelik, 1996). However, there appears to be a lack of investigation on the influence of prewriting techniques on language development in written language. Furthermore, despite the fact that a variety of prewriting techniques have been explored in those studies like video films, reading texts, brainstorming, storytelling, creative drama, comparatively novel techniques such as synectics have not been investigated much. In this regard, this study holds considerable significance as it intends to bridge the gap and be a pioneering study in researching the role of synectics as a particular prewriting technique in language development in L2 writing.

\section{Background}

\subsection{L2 writing: from product to process}

The main approach to L2 writing was process approach to writing with an EAP (English for Academic Purposes) focus within the context of the present study. Therefore, this paper will take L2 writing into account from a process approach perspective. As mentioned in the introduction briefly, process approach originated from the experiential philosophy or learning by doing in the 1970s (Nunan, 1999), which might be considered to be evolved as a reaction to product approach. By the emergence of this approach, the focus on the product shifted to focus on the process. Consequently, L2 writing instruction started to reflect the underlying principles of the approach and involved classroom applications such as idea generation, drafting, and revising and editing. Furthermore, learners were provided with a positive and collaborative environment to go through the stages of the writing process. In addition, formal accuracy was not a matter of concern at least in the initial steps of the process.

Although conceptualizing the construct of writing varies a lot, Silva and Matsuda offer a rather clear definition for it:

[Writing is] one of the modes of linguistic expression and communication - along with speaking and signing - rather than secondary or subservient to speech. It is a manifestation of, as well as the process of manifesting, sociolinguistic, strategic, and grammatical competences mediated by the use of orthographic systems. (2002, p. 253). 
Writing is also a multidimensional construct as it involves "text analytic, composing processes, and sociocontextual perspectives; components (i.e. texts, writers, and contexts); the participants (students, instructors, policy makers, etc.), and basic educational functions (curriculum, instruction, and assessment of L2 writing" (Cumming, 2001, p. 214).

In terms of general characteristics, L2 writing is assumed to be a challenging and demanding skill because creating a fluent, clear, and effective piece of writing requires a number of factors to consider. These factors involve audience, purpose, word choice, content and organization, mechanics, and syntax and grammar (Raimes, 1983). Furthermore, writers are expected to go through recursive and non-linear stages of the writing process and employ particular strategies to maximize the effectiveness of their written text (Raimes, 1983).

Within the context of process approach to writing, the role of the teacher should be one of facilitator, guide, consultant, and judge or provider (Brown, 2001), and additionally, of motivator, resource, and feedback provider (Harmer, 2001).

As shown above, writing is a crucial component of communicative competence, so second language learners' writing skills should be improved through principled approaches and practices.

\subsubsection{Stages of the writing process}

Process approach to writing requires learners to go through a number of stages and employ various strategies until they develop the final product. The terms and number of stages differ in the attempt to describe the writing process in the related literature, which might due to the factors such as teacher preferences or way of instruction, contextual differences like curriculum goals, learning preferences, styles, strategies and the like. However, for the sake of simplicity, a four-stage writing process as described by Oshima and Hogue (2007) will be referred in this paper: prewriting, organizing, writing, and polishing.

Prewriting is the idea generation step in which a variety of techniques could be used to choose a topic and gather ideas to develop it. Actually, it is the stage whereby students experience considerable difficulty in the writing process (Cormack, 1980) since many students feel frustrated or anxious in the beginning phase of writing. Therefore, prewriting appears to be an important stage as it prepares students to form the foundation of their writing. Some common techniques that could be applied in this stage are listing, brainstorming, freewriting, clustering, reading passages related to the topic, doing research, discussing the topic in pairs or groups, drama, etc. Synectics technique which was implemented in the intervention program of the present study could also be used to generate interesting ideas or make connections about the topic.

Organizing is the second step in which the ideas are organized through an outline. It can be a simple outline including a topic sentence (i.e. the sentence that includes a topic and a controlling idea and indicates the subject of the paragraph) and main 
ideas to support the topic sentence. The outline can also be a detailed or a formal one. Its format depends on a set of conventions like letter and number use and indenting. Making an outline before starting to write is essential for building an effective, coherent, and well-developed piece of writing.

Writing is the third stage, whereby a rough draft is written using the outline as a guide. Learners are encouraged to get their ideas developed in the previous stages onto paper without worrying too much for grammar, spelling, or punctuation mistakes in the fastest way possible.

Polishing is the fourth step which involves both revising and editing. Revising is to do with considering the bigger issues of content and organization. It is also about checking the written text in terms of appropriate use of discourse markers and rhetorical conventions. At this point, peer-editing might work well especially if there is a guideline or a checklist for the peer to revise the paper. In editing phase, the writer him/herself checks the paper in terms of the smaller issues of grammar, punctuation, and mechanics to detect and correct the errors if any exists. At last, the final copy is written to be submitted to the instructor; and the instructor checks, evaluates, and gives feedback to the writer of each paper in turn.

As could be noticed from the description of the stages above, writing or the composing process is "a complex, cognitive process that requires sustained intellectual effort over a considerable period of time" (Nunan, 1999, p.273) and has a social, collaborative nature as a result of which learners are expected to gain skills of selfrevision and editing and become autonomous and competent writers in time.

\subsubsection{Research on Prewriting Techniques}

A survey of research on L2 writing reveals that different prewriting techniques have been examined in several studies. For example, Öncü (1999) explored the effects of video films as a prewriting activity on a group of intermediate level learners' argumentative compositions. The findings of the study indicated that there was a significant improvement in writing argumentative composition. In another study, Özçelik (1996) investigated the influence of the use of reading texts as a prewriting activity in low level EFL learners' writing. The results showed that this prewriting technique led to a positive effect on students' writing in the experimental group. Furthermore, Diaw (2009) conducted a case study to examine the impact of storytelling as a prewriting activity in learners' narrative writing in a language arts classroom. The findings revealed that participants enjoyed storytelling; they were also motivated to involve in the constructivist writing process; in addition, interactive storytelling allowed the learners to discover their knowledge of self and the world. In another study, the influence of creative drama as a prewriting strategy on the content and the process of short story writing was explored (Cormack, 1980). One group were given drama, and the other one received a lesson/discussion prewriting instruction. The findings indicated that drama students got higher scores from the first story but significantly higher from the third story with respect to specific categories. Besides, drama students wrote longer stories, used more dialogue, and wrote more frequently 
in the first person. In terms of attitudes, drama students were generally positive about prewriting activities and evaluated their experience as being enjoyable.

There is a scarcity of research investigating the effects of prewriting strategies on language development indicators like fluency and lexical complexity. To the authors' knowledge, there are only two studies available. The first study was undertaken to seek the effects of pre-task planning (idea generation, organization, and goal setting) on learners' essays with respect to writing fluency, grammatical complexity, and lexical complexity (Johnson, Mercado \& Acevedo, 2012). The findings showed that there was a small significant effect of pre-planning condition on writing fluency, but no influence was seen on lexical complexity and grammatical complexity. The second study explored the influence of online student blogs on writing fluency and lexical complexity, and the results revealed that there was a significant increase in fluency and lexical complexity levels (Fellner \& Apple, 2006).

As this review shows, most of the studies given above focused on learner related factors such as motivation, attitudes, interest, awareness, enjoyment, self-discovery, etc. (e.g. Cormack, 1980; Diaw, 2003) while very few of them explored the effects of using prewriting techniques on writing skills or improvement in writing rhetorical modes (e.g. Öncü, 1999; Özçelik, 1996). In this respect, there appears to be a lack of research investigating the effects of a prewriting technique on writing skills in terms of developmental measures like fluency and lexical complexity. The present study is an attempt to bridge this gap.

\subsection{Synectics Model}

\subsubsection{Background of the Synectics Model}

The word 'synectics' has been derived from Greek roots syn (bring together) and ectics (diverse elements), and it basically refers to a structured technique for problemsolving or idea-generation. The creator of the Synectics Model (henceforth SM), Gordon, defines the term as "joining together of different and apparently irrelevant elements" (1961, p. 3). Weaver and Prince also define it as "a creative problem-solving process that carries participants from the analysis of problems to the generation and development of new ideas" (1990, p. 378).

The origin of synectics goes back to the invention meetings of a group of individuals who created metaphors for developing new industrial products. Tape recordings of those meetings were examined by Gordon and his team (Gordon, 1961). Through this examination, they were able to discover the psychological states of the creative process that promoted divergent and metaphorical thinking (Seligmann, 2007). Consequently, this research led to the development of the synectics process (Weaver \& Prince, 1990).

According to Gordon (1961), synectics research is based on three hypotheses. The first hypothesis predicts that creativity is a potential human capacity which could be developed through certain processes or techniques. The second hypothesis assumes that emotions and irrationality are essential in promoting creativity; and the third 
one suggests that understanding the problem is as significant as solving the problem and producing a creative outcome. Based on these hypotheses, the SM is a means to support the promotion of creativity and problem-solving capacity.

Connection-making element is central to the synectics process, which is achieved with the help of metaphor building. Metaphor which includes "all figures of speech (e.g. simile, personification, and oxymoron) that join together different and apparently irrelevant elements through the use of analogy" (Estes, Mintz, \& Gunter, 2010, p. 147) is the backbone of the synectics process.

Synectics process includes the implementation of systematic use of three forms of metaphor. A direct analogy, known also as simile, is "a direct comparison between two objects, ideas or concepts" (Estes et al., 2010, p. 147). An example for this kind of metaphor could be the comparison between the veins in our bodies and a plumbing system. The second form of metaphor is personal analogy (personification) which lets learners to feel empathy with the object or idea in hand. The third form, "symbolic analogy (oxymoron), or compressed conflict, involves descriptions that appear to be contradictory but are actually creatively insightful". In the authors' words, it is like a 'fight' among words. This metaphorical fight allows learners to adopt a new viewpoint about the idea which is being explored as a result of group interaction.

To conclude, synectics is a structured technique designed for generating ideas, solving problems, and producing novelty through activation of psychological, conscious, and systematic mechanisms that are stimulated by making connections between seemingly irrelevant elements using different forms of metaphor.

\subsubsection{Synectics in education}

Synectics was originally developed for industry based environments while its use has been extended into a range of contexts. In education, synectics is an instructional model aiming to stimulate learners' problem-solving and creative thinking skills by making sense of new information through specifically planned techniques.

In terms of theoretical underpinnings, it appears to be in accordance with the constructivist learning theory and reflective thinking (Seligmann, 2007; Walker, 2009). The view that learners construct their own reality or knowledge by making personal connections between what they know and what they are to learn rather than solely storing the knowledge transferred by a teacher is truly in line with the underlying principles of the SM, which is achieved through the use of metaphor.

The model also shares some principles of social-interactionism whereby learning is considered as a problem solving process taking place in interaction with other people in a cooperative and collaborative manner. Although synectics is a technique that could be used individually, working in groups might help learners see situations differently with the use of alternative viewpoints (Seligmann, 2007).

The SM also inherits several features that tend to support the principles of democracy education by letting learners listen to and appreciate each other's ideas respectfully, try to understand others' points of view, or vote for doing some selections 
as a class at different points of time during the sessions through constructive peer interaction.

As for the final features underlying the SM, it lends itself to the accommodation of diverse thinkers and various learning styles as it has the tools of three kinds of metaphor to gap the bridge between the right and left brain hemisphere, thereby tapping all kinds of learners with different multiple intelligences and Mindstyles (Seligmann, 2007).

In sum, synectics appears to be an innovative instructional model that could be employed to enhance learners' creative thinking capacity and problem-solving skills. It also provides the base for cooperative and collaborative learning. Furthermore, the use of synectics in education makes it possible to reach a variety of learners with different learning and thinking styles, and intelligences. Last but not least, it might be possible to obtain various educational gains by the implementation of synectics in different curricular areas.

\subsubsection{Versions of the Synectics Model}

There are two main versions or operational mechanisms of the SM as identified by Gordon (1961): Making the Familiar Strange (henceforth MFS) and Making the Strange Familiar (henceforth MSF). The first version is more like an analytical step because it first requires individuals to understand the problem. It should also be noted that this understanding is apt to change in the course of the process. This version "helps students to see new patterns and relationships from previously learned knowledge and understandings" (Estes et al., 2010, p. 150). In other words, it is a bridge between the known and unknown. The second version, MSF, becomes the focus of the problem-stating, problem-solving process by "help[ing] make new knowledge more meaningful by bridging new and familiar information" (p. 150). Both of these versions are essential in the synectics process as they lead individuals to involve in the psychological states basic to the creative process. However, depending on the nature of the subject matter to be taught or the aim of a particular research study, a specific version is preferred and utilized. In this study, MFS version was used.

\subsubsection{Research on the Synectics Model}

Even though there are plenty of resources explaining theoretical features of the concept of synectics and main steps involved in its implementation, the number of the research studies exploring the use of the model is comparatively limited.

The review of research on synectics could be grouped into two. The first group presents a review of studies investigating the influence of synectics in FLE, and the second one includes a review of research on its effects in other curricular areas. Only two studies are available in the former group. The first study investigated the use of the SM on vocabulary learning performance, attitudes, and desire to learn English of a group of B1 level $8^{\text {th }}$ graders in the Turkish context (Asmalı \& Dilbaz Sayın, 2016). The findings obtained from the post-tests revealed that there were no statistically significant differences between the students in two groups in terms of attitudes and 
desire to learn English; however, the students' vocabulary learning performance improved significantly in the experimental group. The second study sought the influence of synectics and journal writing techniques on a group of EFL students' creativity (Fatemipour \& Kordnaeej, 2014). The results showed that both synectics and journal writing techniques had a significant effect on the promotion of creativity. On the other hand, the synectics group outperformed the journal group. In addition, the participants had generally positive attitudes towards synectics technique.

The second group of studies have mainly been carried out in English Language Art classrooms and science courses. The studies implemented in English Language Arts courses involved the study of variables such as teacher attitudes towards the use of synectics, and learners' creative writing growth (Burk, 2005; Keyes, 2006), analogical and divergent thinking ability, and attitudes toward writing (Heavilin, 1982), and vocabulary and reading skills development (Brown, 1980). As for the studies undertaken in science courses, they explored the impact of the model on students' potential in developing original products, identifying problematic situations, and offering practical solutions to them (Ercan, 2010), creative thinking ability, academic achievement, and achievement motivation, achievement in the science course (Kleiner, 1991; Paltasingh, 2008; Pany, 2008; Patil, 2012).

As could be inferred from the review above, although synectics has proved to promote creative thinking in different curricular areas and vocabulary learning in an EFL context, there seems to be a scarcity of research investigating its effects with respect to language development in L2 writing.

\subsection{Research questions}

The main objective of this study is to explore the effects synectics as a prewriting technique on learners' writing fluency and lexical complexity in a tertiary level English course. In addition, this study intends to discover learners' perceptions of their experience with respect to language development. Based on these objectives, the following research questions were sought to answer:

1. Is there a significant change in learners' writing fluency throughout the program?

2. Is there a significant change in learners' lexical complexity throughout the program?

3. How do the learners perceive their experience in relation to language development in their writing?

\section{Method}

\subsection{Research design}

The present study adopts a mixed research study design that combines both quantitative and qualitative approaches during the data collection and analysis phases. In order to ensure triangulation and to interpret the results from different 
perspectives, both quantitative and qualitative data collection methods were made use of. The specific design of the quantitative part of the study is the repeated measures design. The reason for using this design is to observe participants' progress in writing fluency and lexical complexity over time. Qualitative data were collected from the participants as the main program shareholders by carrying out semistructured interviews.

\subsection{Participant characteristics}

The research site of the study is the School of Foreign Languages at Çanakkale Onsekiz Mart University in Turkey. The present study was carried out in the English Language Teaching and English Language Literature Preparatory Program, which serves students instruction in English for one academic term or year. The students enrolled in this program are expected to reach a level of $\mathrm{C} 1$ by gaining skills and competence to meet academic English requirements in their future studies and also to use the language effectively in professional and social spheres. It offers four courses (i.e. Listening and Speaking, Reading, Writing, and Basic English), and writing course component was chosen for the conduction of this study. The total number of weekly course hours is 28 , and the size of the program is around 80 students.

The sampling was convenient sampling. The implementation of this study was realized with one intact group involved in this program during the spring term of academic year. It consisted of 18 female and 2 male students. Their age ranged from 18 to 21 . All of them were native speakers of Turkish. Their consent was obtained prior to the implementation of the program.

With respect to the participants' academic achievement, they had a moderate level of achievement in writing and Basic English courses. More specifically, they had a mean of 67.5 for the writing course and a mean of 71.3 for the Basic English course by the end of the fall term.

As for the aspects regarding writing, the students did not have considerable L2 writing instruction experiences in their previous education. More specifically, only 7 students reported that they partly had writing instruction in high school. Furthermore, they had a moderate level of anxiety in writing in English $(M=2.8)$. Finally, they had a fairly high level of comfort in self-expression in writing in English $(M=3.4)$.

In terms of the participants involved in the semi-structured interviews by the end of the study, 9 students volunteered to be interviewed. In order to preserve the anonymity of the students, they were given codes from S1 to S9 while reporting the findings. All the students were female. Their age ranged between 18 and 21, and their grade point averages (GPA) were between 63 and 87 .

\subsection{Data collection instruments}

\subsubsection{Writing tasks}


In order to seek the effects of the synectics program on the developmental measures of fluency and lexical complexity in written language, the participants were required to write paragraphs about specific topics at three points of time during the course of the study. The topics of the writing tasks were determined by the participants during the synectics sessions through voting. The participants were instructed to write the paragraphs in line with paragraph writing rules covered in the writing course during the academic year. They were asked to write a paragraph of 150-200 words in approximately 40 minutes.

\subsubsection{Semi-structured interviews}

To elicit the participants' evaluation of their experience of being a part of the program, semi-structured interviews were conducted with a volunteering group of students. With this reason in mind, a set of interview questions were prepared in line with the objectives of the study. After the questions were written by the researchers, they were examined and evaluated by an expert in terms of face and content validity, wording, clarity, and whether they were in line with the objectives of the study. Subsequently, required alterations were made on the questions.

\subsection{Data collection procedures}

After the official permission was received, the participants were informed about the purpose, content, length, and procedures of the study. Before the real program started, a pilot session was held with another group of students to see the lacking points of the implementation of the program and what could be changed. The implementation of the intervention program covered a period of seven weeks. During the program, six synectics sessions were held with the participants. Finally, semistructured interviews were hold with a group of voluntary participants. The outline of the program is illustrated in Table 1:

Table 1. The Synectics Program

\begin{tabular}{|c|c|c|c|c|c|c|c|c|}
\hline Pre- & \multicolumn{7}{|c|}{ The synectics program } & Post- \\
\hline & $\begin{array}{l}1^{\text {st }} \\
\text { session }\end{array}$ & $\begin{array}{l}2^{\text {nd }} \\
\text { session }\end{array}$ & $\begin{array}{l}3^{\text {rd }} \\
\text { session }\end{array}$ & & $\begin{array}{l}4^{\text {th }} \\
\text { session }\end{array}$ & $\begin{array}{l}5^{\text {th }} \\
\text { session }\end{array}$ & $\begin{array}{l}6^{\text {th }} \\
\text { session }\end{array}$ & \multirow[b]{2}{*}{ 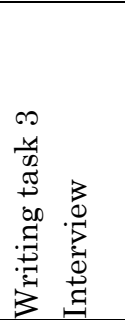 } \\
\hline 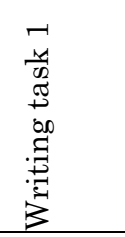 & $\begin{array}{l}\text { Topic: } \\
\text { Falling } \\
\text { in love }\end{array}$ & $\begin{array}{l}\text { Topic: } \\
\text { Racism }\end{array}$ & $\begin{array}{l}\text { Topic: } \\
\text { Freedom }\end{array}$ & 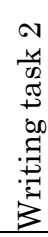 & $\begin{array}{l}\text { Topic: } \\
\text { Dreams }\end{array}$ & $\begin{array}{l}\text { Topic: } \\
\text { Responsi } \\
\text { bility }\end{array}$ & $\begin{array}{l}\text { Topic: } \\
\text { Justice }\end{array}$ & \\
\hline
\end{tabular}

The synectics program including six sessions of synectics used as a prewriting technique began with the introduction of the technique to the participants. Then an exemplary lesson was demonstrated before the first session. After that, the participants were told to form groups to work together during each session. As a 
result, there were totally five groups with four students in each, and the students remained in their determined groups throughout the program.

A synectics session began with greeting and establishing rapport and proceeded with lead-in and main activities. Giving the participants a right to determine the topic of the writing task and also the categories for direct analogies was one of the aims of the study so that they could have a sense of ownership of the task and involve in the activity more willingly. Some examples for those categories were plants, animals, sports, nature, occupations, space, etc.

The main activity was composed of seven main steps (see Appendix A for detailed explanation).

In order to simplify the complicated nature of the activity for the students, a graphic organizer was used by the researchers, which displayed each stage of the activity in different columns, and each stage is represented with a simpler term such as definition, similar, feels like, opposite, similar, and synthesis. In this way, the students could follow the stages more comfortably and confidently (see Appendix B).

\subsection{Procedures for data analysis}

In order to determine the participants' writing fluency and lexical complexity, an online text analysis program was used. The program is called Vocabprofile (VP), which was based on Laufer and Nation's Lexical Proficiency Profile (1994), and it serves research and teaching purposes about vocabulary development (http://www.lextutor.ca/vp/comp/). VP includes several text analysis tools. For this study, VP-Compleat (Classic) version, which analyzes texts through parameters such as tokens (words in text), types (different words), type-token ratio, and word families, was utilized. In this study, the number of tokens was considered to account for writing fluency, and type-token ratio was for lexical complexity. More specifically, fluency refers to "access of more words and more structures in a limited time" (WolfeQuintero, Inagaki \& Kim, 1998, p. 14) and lexical complexity means "availability and quick access of a wide variety of basic and sophisticated words" (p.101). The data obtained from the analysis of the texts were subjected to non-parametric Friedman Test for repeated measures and Wilcoxon Signed Ranks Test for pairwise comparison since the data did not show a normal distribution. For the statistical analysis, SPSS 20 was used.

As for the qualitative data from the semi-structured interviews, inductive content analysis technique was employed. After the interviews were recorded, they were transcribed, and codes, themes, and categories were identified. To ensure the interrater reliability of the analysis, nearly $30 \%$ of the data were analyzed in a verbatim fashion by two independent raters, and the parallelism between the two sets of analyses was found to be $93 \%$, which pointed to a high level of consistency between the raters. After the entire data were analyzed, a table was formed to display the categories and themes, and quotations from the transcripts were also included while presenting the findings. 


\section{Results}

\subsection{Results for the writing fluency and lexical complexity}

In order to seek the effects of synectics on the participants' writing fluency and lexical complexity, the texts written at three intervals (pre-, mid-, and post- synectics program) were analyzed through Vocabprofile (VP). The data obtained from these procedures were analyzed through statistical tests like descriptive statistics, Friedman Test for repeated measures and Wilcoxon Signed Ranks Test for pairwise comparisons. First of all, descriptive statistics was performed in order to find out the mean values of fluency and lexical complexity measures from the texts written at three intervals (see Table 2).

Table 2. Pre, Mid, and Post-test Scores for Writing Fluency and Lexical Complexity

\begin{tabular}{lllllll}
\hline Category & Pre & & Mid & \multicolumn{3}{l}{ Post } \\
\hline & $M$ & $S D$ & $M$ & $S D$ & $M$ & $S D$ \\
\hline Writing fluency & 118.55 & 35.91 & 136.30 & 45.23 & 151.95 & 28,83 \\
\hline Lexical complexity & .58 & .07 & .59 & .08 & .57 & .06 \\
\hline
\end{tabular}

The findings in Table 2 indicate that the mean values of pre, mid, and post-test fluency measures appear to have increased, but the mean values of pre, mid, and posttest lexical complexity remained fairly the same. In order to see whether these changes point to statistically significant differences, a non-parametric Friedman Test was run. Table 3 displays the findings from the test.

Table 3. Differences among Pre, Mid, and Post-tests for Writing Fluency and Lexical Complexity

\begin{tabular}{llllllll}
\hline Category & Time & $N$ & $M$ & $S D$ & Df & $X^{2}$ & $p$ \\
\hline \multirow{2}{*}{ Writing } & Pre & 20 & 118.55 & 35.91 & & & \\
Fluency & Mid & 20 & 136.30 & 45.23 & 2 & 9.700 & .008 \\
& Post & 20 & 151.95 & 28.83 & & & \\
\hline \multirow{2}{*}{ Lexical } & Pre & 20 & .58 & .06887 & & & .228 \\
complexity & Mid & 20 & .59 & .07867 & 2 & .892 \\
& Post & 20 & .57 & .06221 & & & \\
\hline
\end{tabular}

According to Table 3 , there was not a significant difference among the three measures of lexical complexity $\left(\mathrm{X}^{2}(2)=.23, p=.89\right)$. In contrast, a significant difference among the three measures of writing fluency $\left(\mathrm{X}_{(2)}=9.70, p=.008\right)$ was detected. In order to identify which measures of fluency in particular differ from each other, a Wilcoxon Signed Ranks Test for pairwise comparisons was run as post hoc, and a Bonferroni adjustment on the results from the test was used (see Table 4). 
Table 4. Pairwise Comparisons of Pre, Mid, and Post-test for Writing Fluency

\begin{tabular}{|c|c|c|c|c|c|c|}
\hline $\begin{array}{l}\text { Fluency test } \\
\text { Pairs }\end{array}$ & & $N$ & $\begin{array}{l}\text { Mean } \\
\text { Rank }\end{array}$ & Sum of Ranks & $Z$ & $p$ \\
\hline \multirow{3}{*}{ Pre and Post } & Negative Ranks & $4^{\mathrm{a}}$ & 4.50 & 18.00 & \multirow{3}{*}{$-3.248^{a}$} & \multirow{3}{*}{.001} \\
\hline & Positive Ranks & $16^{\mathrm{b}}$ & 12.00 & 192.00 & & \\
\hline & Ties & $0^{c}$ & & & & \\
\hline \multirow{3}{*}{ Pre and Mid } & Negative Ranks & $5^{\mathrm{a}}$ & 9.80 & 49.00 & \multirow{3}{*}{$-2.091^{\mathrm{a}}$} & \multirow{3}{*}{.037} \\
\hline & Positive Ranks & $15^{\mathrm{b}}$ & 10.73 & 161.00 & & \\
\hline & Ties & $0^{c}$ & & & & \\
\hline \multirow{3}{*}{ Mid and Post } & Negative Ranks & $8^{\mathrm{a}}$ & 7.56 & 60.50 & \multirow{3}{*}{$-1.661^{\mathrm{a}}$} & \multirow{3}{*}{.097} \\
\hline & Positive Ranks & $12^{\mathrm{b}}$ & 12.46 & 149.50 & & \\
\hline & Ties & $0^{\mathrm{c}}$ & & & & \\
\hline
\end{tabular}

The results of the analysis, as shown in Table 4, indicate that there was a significant difference only between fluency pre-test and post-test, and also the effect size for this analysis was found to indicate a medium to large effect size which shows that the result has a practical significance. $(z=-2.09, p=.001, r=-.51)$.

However, the differences between fluency pre-test and mid-test $(z=-2.0091, p=$ $.037)$, and mid-test and post-test $(z=-1.66, \mathrm{p}>.05)$ were not statistically significant. These findings show that although there did not appear to be a significant increase in participants' writing fluency in shorter periods of time, it increased significantly in the long term.

To summarize the findings in relation to the first two research questions, the participants' development in writing fluency increased significantly at the end of the program. However, their improvement with respect to lexical complexity remained the same during the study.

\subsection{Results for the participants' perceived experiences}

The results of the qualitative data analysis revealed that the participants had mostly positive perceptions about their synectics experience. The three categories with respect to positive issues were vocabulary learning, improvement of writing skills, and attitudes to writing (see Table 5).

Table 5. Positive Issues about the Use of Synectics as a Prewriting Technique

\begin{tabular}{|c|c|c|}
\hline Categories & Themes & Participant Codes \\
\hline & Learning new vocabulary items & S2-S3-S4-S5-S6-S7-S9 \\
\hline 1. Vocabulary learning & Retention of new vocabulary items & S1-S3 \\
\hline \multirow{2}{*}{$\begin{array}{l}\text { 2. Improvement of writing } \\
\text { skills }\end{array}$} & Contribution to paragraph writing & S1-S3-S4-S6-S9 \\
\hline & Comfort in writing & S3-S4-S6-S7 \\
\hline 3. Attitudes to writing/the & Positive attitude to writing & S1-S2-S4-S6-S8 \\
\hline
\end{tabular}


The most frequent category reflecting a positive perception was vocabulary learning. The first theme in this category was learning new vocabulary items. Most of the participants stated that the synectics technique offered them an opportunity to learn more new vocabulary items. For example, S7's response points out the effectiveness of synectics and also the use of group work in vocabulary learning.

"We learned new words. When the others shared different words that we didn't know, we learned what they knew."

S6 pointed to the contribution of dictionaries and other groups' ideas in learning new words.

"In the preparation (initial) stage of the activity, we learn new words from the dictionary and the other groups."

The quotations above signal the importance of being individually active through the use of dictionaries and other sources, and also the power of interaction with the group members or classmates in vocabulary learning. As a result, it is possible to state that the synectics technique is conducive to vocabulary learning as it inherently necessitates being both individually and collectively active in each stage of the activity.

The second theme within vocabulary learning category is the retention of new vocabulary items. For example, two participants made the following comments.

(S9) "I believe there is an improvement in my vocabulary because when we write, we need words, and as we use them we retain them more."

(S3) "Everybody utters different adjectives that I don't know. When this happens, I learn new words. Most of these words become permanent as we use them while writing."

These comments indicate that students did not only learn new vocabulary items during the synectics activity, but also retained them because they used most of these words in their texts. Another factor that might help them remember many of the words could be the fact that those words were repeated throughout the activity as the teacher tried to summarize the groups' suggested ideas, and the students vote for the best ideas. Moreover, all the ideas and vocabulary items were projected onto the board so that the students had also a visual reference to them throughout the session.

Improvement of writing skills is the second category. Some of the students reported that the synectics technique contributed to their paragraph writing; and some of them said they gained comfort in writing. The following quotations from the interviews reflect this theme:

(S3) "Since we work in groups, more ideas come out; in this case, writing becomes much easier for me... I normally have difficulty in writing the introduction and the ending of a text. However, this becomes easier for me when we use the synectics 
technique. I know how to start and end it because I get inspired from the ideas that came out during the activity."

(S4) "I don't spend time thinking how to begin the sentence; I start to write comfortably."

(S6) "Using the data that emerged from the synectics group work makes our writing easier... It's a complicated technique, but it makes my individual writing easier."

These findings could be interpreted with regard to the importance of the prewriting stage of the writing process. As discussed previously, prewriting appears to be an important stage since it prepares students to form the foundation of their writing through using certain techniques or activities to generate ideas. In this respect, it could be suggested that the synectics technique as a prewriting activity seems to fulfil this function in that students in this study appeared to have gained comfort and a sense of improvement in writing in English.

Attitudes to writing/the writing course, the third category, was another positive issue about the use of the synectics technique. Positive attitude to writing and higher motivation are the themes under this category. Some of the corresponding excerpts from the transcripts are presented below:

(S1) When we have a synectics activity, I participate in the lesson more eagerly. In a way, I have a more positive attitude to the course."

(S5) "I have a rather positive attitude to writing. In fact, I started to like writing more with synectics."

(S6) "I had a negative attitude to writing at the beginning of the academic year. I couldn't write at that time, but now I can write. I can say my attitude turned into a bit more positive. I can produce more ideas thanks to this technique."

It could be drawn from these responses that the implementation of the synectics technique in this study had a positive effect on participants' attitude to writing and the writing course, and motivation to write.

Although the participants' perceived experiences were mostly positive, there were also a few negative issues which revealed two categories, i.e. the length of the synectics session and disagreement (see Table 6).

Table 6. Negative Issues about the Use of Synectics as a Prewriting Technique

\begin{tabular}{lll}
\hline Categories & Themes & Participant Codes \\
\hline 1. Length of the synectics session & Time-taking & S1-S2-S3-S6-S7 \\
2. Disagreement & Difficulty in deciding at ideas in group & S1-S9 \\
& Dominance of some peers' ideas & S4-S9 \\
\hline
\end{tabular}

As Table 6 indicates, the participants thought that the synectics activity tends to be very time-taking as a prewriting activity. This could be stemming from the fact that a great deal of time is needed to accomplish each successive stage of metaphor building 
to complete the whole task. Therefore, some adaptations regarding the timing could be made in order to overcome this drawback. In addition, although much more positive responses were elicited about the advantages and effectiveness of group work, a few students pointed to a drawback of group work in terms of disagreement during the idea selection in groups.

\subsection{Discussion of findings for the writing fluency and lexical complexity}

The results of the findings from the quantitative data indicate that the participants' writing fluency increased significantly. The measurements carried out at three intervals showed a continuous rise. However, only pre-test post-test difference found to be statistically significant. The finding in relation to the increase in learners' writing fluency was also reflected in the qualitative analyses. As a result, it could be concluded that the synectics technique had a positive effect on the improvement of writing fluency, i.e. the number of words in a text. This might show that synectics activates learners' idea generation capacity, which results in acceleration in the number of words. On the other hand, the findings revealed that the synectics programme did not lead to a statistically meaningful increase in lexical. Although the participants generated a wealth of vocabulary items through certain strategies peculiar to the synectics technique, they did not seem to have used the new or distinct ones emerged during the sessions. This might show that learners might have preferred to use the items from their active vocabulary instead of the ones produced during the activity, which might indicate the importance of using new vocabulary all through the learning process.

To the authors' knowledge, no other study is available that investigated the effects of synectics as a prewriting technique on developmental measures of writing fluency and lexical complexity in written language. However, the results of several studies implementing various prewriting techniques have also indicated some educational gains. For example, Öncü (1999) found out that the use of video films led to an improvement in writing argumentative compositions. Furthermore, Özçelik's (1996) study pointed that the use of reading texts resulted in a significant increase in learners' scores regarding content, organization, vocabulary, and language use. However, the results of a study on the impact of brainstorming as a prewriting strategy revealed that there was not a significant influence of the strategy on learners' writing development (Hashempour, Rostampour \& Behjat, 2015), which might be taken as an indicator of the effect of certain learner and/or contextual factors that may have an impact on the successful and effective implementation of these prewriting techniques. On the other hand, one of the few studies investigating developmental measures of fluency and lexical complexity which was carried out by Fellner and Apple (2006) showed that the participants' fluency and word frequency levels increased significantly at the end of the program.

In conclusion, despite the limitation of the group size, the results of this study appear to prove that synectics might be effective in improving writing fluency in the 
long term. Therefore, it might be concluded that synectics could be applied in the writing process as an alternative prewriting technique.

\subsection{Discussion of findings for the participants' perceived experiences}

The analysis of the qualitative data gathered from the semi-structured interviews yielded three broad categories, namely vocabulary learning, improvement of writing skills, attitudes to writing/the writing course. Most of the participants stated that the technique helped them learn and retain more vocabulary items, which also supports the results of the quantitative data on writing fluency. They also emphasized that their writing skills improved considerably. Although this study did not primarily focus on the development of general writing skills of the learners, the qualitative data analysis revealed considerable gains in this area as well. This result coincides with those of other studies (e.g. Cormack, 1980; Öncü, 1999) where positive correlations were found between language proficiency and writing competence. Thus, it can be argued that the significant difference in writing fluency detected in this study might be related to learners' language proficiency. To sum up, the participants' opinions regarding their experience with the synectics technique were generally positive in terms of both linguistic and writing skills development, and psychological constructs such as attitudes and motivation.

\subsection{Limitations}

Like any educational sciences study, this study also comprises several limitations. First of all, the findings of this study are limited to the size of the sample group, which was composed of 20 students attending the English preparatory class at the School of Foreign Languages at a Western Turkish university. In addition, not all the students were present in each synectics session during the implementation of the program, which means there were a few absentees who could not receive the instruction at some points of the synectics program. Because of these two reasons related to the sample, the results of this study cannot be generalized for all population of learners and contexts where English is instructed as a foreign language. Second, the data collection process and implementation of the program covered a period of only six weeks, which might be regarded a short period of time. Therefore, it is questionable whether different results could have been obtained if the length of the study had been longer or shorter.

\section{Conclusions and Implications}

The primary goal of this study was to explore the effects of synectics as a prewriting technique on developmental measures of fluency and lexical complexity in written language. The results of the study indicated that learners' writing fluency increased significantly between pre-test and post-test measures, which comes to mean that synectics seems to provide more positive effects in the long term. This finding could be attributed to the fact that the synectics technique involves primarily a vocabulary 
activation and expansion activity. In this respect, the finding in relation to the increase in learners' writing fluency might be regarded as an expected outcome as the technique appears to present learners a large repertoire of vocabulary items to use while composing their texts. In other words, since the nature of the technique lends itself to generating plenty of ideas throughout its implementation, it is not surprising that there was a significant growth in learners' writing fluency. In contrast, learners' lexical complexity appeared to remain fairly the same throughout the programme. This result could be explained by the fact that although the vocabulary items that were produced by the learners in the sessions showed great variation, they might have used the items from their active vocabulary instead of the new or distinct ones suggested during the activity while composing their texts.

From the participants' point of view, some conclusions worthy of consideration related to the findings of the qualitative data could also be drawn. As explained above, the participants tended to have mostly positive opinions regarding their experience. This is actually an expected result as the features inherent in the SM make it appealing to learners. First of all, the design of the technique, which basically involves connection-making through metaphor, may appear to be what makes their experience positive for the students. In addition, the mechanisms of synectics process require participants to work in a cooperative and collaborative manner when they are producing analogies to improve their understandings of new concepts, and this is likely to produce educationally valuable results. Moreover, as discussed in the background, the SM appears to tap all kinds of learners with different multiple intelligences, various learning styles, and diverse thinkers as it has the tools of three kinds of metaphor to gap the bridge between the right and left brain hemisphere. It also helps build a more learner-centred classroom atmosphere whereby learners actively engage in learning (Seligman, 2007).

These results also carry several important implications for the implementation of the SM in the classroom. First of all, based on the findings and researchers' experience, it was realized that synectics could be used as a prewriting technique despite a couple of drawbacks or points to be cautious about. An important educational implication arises from the result regarding the lexical complexity. It has been seen that lexical complexity is not a trait in the language production of learners that can develop automatically. Therefore, it seems essential for foreign language educators employing the synectics technique to take a couple of instructional moves to help learners improve this trait. One way to ensure this could be through distributing the vocabulary lists produced during each session to students and directing and motivating them to use especially the distinct vocabulary items from the lists in their texts so that those words could become a part of their active vocabulary. In addition, students could be given a minimum number of those items to use in their texts. Another way to make learners to use those words is to project the word lists onto the board throughout the activity; therefore, when the writing action starts, they can have a continuous visual reference to the lists and use the words actively in their texts. Alternatively, those lists could be shared with the students through 
photocopying or downloading them into an online sharing programme. In short, teachers need to make it sure that the student-generated lists from the synectics sessions are actively used.

Another significant educational implication is about the timing of a synectics session. As each session tends to last long, students might show signs of fatigue and boredom. With the purpose of overcoming this problem, some adaptations could be made. For example, teachers should set time limits for groups for brainstorming and idea generation so that the planned lesson time should not be exceeded. Alternatively, the groups could be kept fixed for a determined period of time in order not to lose time for arranging groups in each session. Teacher monitoring is also required and a set of rules for choosing ideas to offer to class during in-group idea generation processes should be established.

It could also be suggested that the SM be implemented in various educational contexts, with different age groups and proficiency levels, and also in different courses such as speaking, vocabulary, reading, etc. In addition, the results obtained from the study might interest the curriculum developers of English Language Teaching Departments as the synectics technique might be included among prewriting techniques in training pre-service English teachers to teach writing skills. Furthermore, foreign language teachers could be informed and trained about the use of the synectics technique in FLE through in-service teacher training courses.

There are also a couple of implications arisen for researchers. The effect of other learning environments which were a part of the large preparatory programme running at the time of research might have affected the results of the study. This calls for an important implication for future research. Such an instructional model could be experimented with a group of participants who are enrolled in a single course on which other courses or learning environments might not have an effect. For example, it might be conducted in a non-formal and non-assessed setting such as a private language course so that the effect of other external factors could be minimized. In addition, in order to draw more confident conclusions regarding the effects of the SM, true experimental design with a control group could be employed in future research.

On the whole, this study points out that synectics as a prewriting technique can be used in the English language classrooms at tertiary level as it causes a significant development in learners' writing fluency. Furthermore, the technique can be refined by letting students get exposed to a wide range and number of lexical items through certain instructional moves to induce the development of lexical complexity as the researchers experienced in the class.

\section{References}

Açıkgöz Karakaş, Ö. (2011). Yaratıcı yazma tekniklerinin İnilizce yazma becerisini geliştirmeye etkisi [The effect of the creative writing techniques to writing skills in English]. Unpublished master's thesis, Osmangazi University, Eskişehir, Turkey. 
Asmall, M., \& Dilbaz Sayın, S. S. (2016). The effects of the Synectics Model on vocabulary learning, attitude, and desire to learn English. Asian EFL Journal, 18(3), 41-60.

Brown, H. D. (2001). Teaching by principles. New York, NY: Longman.

Brown, T. K. (1980). Effect of Synectics Education Systems' connection making skills on learning of Title I sixth graders. Unpublished doctoral dissertation, Temple University, Philadelphia, PA.

Burks, C. G. (2005). Combating the Bartleby Syndrome with synectics: Examining teacher attitudes and the influences on student writing (Unpublished Doctoral Dissertation). University of Houston, Texas.

Cormack, R. (1980). Creative drama in the writing process: The impact on elementary students' short stories. Unpublished master's thesis, The University of Northern British Columbia, British Columbia, Canada.

Cumming, A. (2001). The difficulty of standards: For example in L2 writing. In T. Silva \& P. K. Matsuda (Eds.), On second language writing (pp. 209-229). Mahwah, NJ: Lawrence Erlbaum Associates.

Diaw, P. W. (2009). Case study: The influence of storytelling as a prewriting activity (in the writing process) on narrative writing in the No Child Left behind Learning Environment. Unpublished doctoral thesis, Saint Joseph's University, Philadelphia.

Ercan, S. (2010). Fen Öğretiminde Yaratıcı Düşünme Tekniklerinden Sinektik Kullanımına Yönelik Bir Eylem Araştırması [An action research related to use of synectics technique in science education]. Unpublished master's thesis, Sakarya University, Sakarya, Turkey.

Estes, T. H., Mintz, S. L. \& Gunter, M. A. (2010). Instruction: A models approach. London: Pearson.

Fatemipour, H. \& Kordnaeej, M. (2014). The effect of synectics and journal creative writing techniques on EFL students' creativity. International Journal of Language Learning and Applied Linguistics World, 7 (3), 412-424. Retrieved from http://www.ijllalw.org/finalversion7331.pdf.

Fellner, T. \& Apple, M. (2006). Developing writing fluency and lexical complexity with blogs. The JALT CALL Journal, 2(1), 15-26.

Gordon, W. J. J. (1961). Synectics: The development of creative capacity. New York: Harper and Row.

Harmer, J. (2001). The practice of English language teaching. Essex: Longman.

Hashempour, Z., Rostampour, M. \& Behjat, F. (2015). The effect of brainstorming as a prewriting strategy on EFL advanced learners' writing ability. Journal of Applied Linguistics and Language Research, 2(1), 86-99.

Heavilin, B. A. (1982). The use of synectics as an aid to invention in college composition. (Report No. 143) Muncie, IN: Ball State University. (ERIC Document Reproduction Service No. ED 246426).

Johnson, M. D., Mercado, L. \& Acevedo, A. (2012). The effect of planning sub-processes on L2 writing fluency, grammatical complexity, and lexical complexity. Journal of Second Language Writing, 21(3), 264-282. Retrieved from https://doi.org/10.1016/j.jslw.2012.05.011

Keyes, D. K. (2006). Metaphorical voices: Secondary students' exploration into multidimensional perspectives in literature and creative writing using the Synectics Model. Unpublished doctoral dissertation, University of Houston, Texas.

Kleiner, C. S. (1991). The effects of synectics training on students' creativity and Achievement. Unpublished doctor of education dissertation, United States International University, San Diego.

Laufer, B. \& Nation, P. (1994). Vocabulary size and use: Lexical richness in L2 written production. Applied Linguistics, 16(3), 307-322. 
Nunan, D. (1999). Second language teaching and learning. Boston, Massachusetts: Heinle\&Heinle Publishers.

Oshima, A. \& Hogue, A. (2007). Introduction to academic writing. NY: Pearson Longman.

Öncü, F. (1999). Using video as a pre-writing activity in writing. Unpublished master's thesis. Anadolu University, Eskişehir, Turkey.

Özbek, A. (2006). The effect of a creative thinking programme on EFL students' attitudes towards their own creativity. Unpublished master's thesis, Gazi University, Ankara, Turkey.

Özçelik, M. (1996). A study of teaching writing through reading to low-level prep- school students. Unpublished master's thesis, Anadolu University, Eskişehir, Turkey.

Paltasingh, S. (2008). Impact of Synectics Model of teaching in life science to develop creativity among pupils. EJAIAER, 20(3-4), 66-69. Retrieved from http://www.ejournal. aiaer.net/vol20208/9.htm.

Pany, S. (2008). Effectiveness of Synectics Model of teaching in enhancing creativity,academic achievement and achievement motivation of learners. EJAIAER, 20(1\&2), 63-65. Retrieved from http://www.aiaer.net/ejournal/vol20108/11.htm.

Patil, R. (2012). Effectiveness of Synectics Model (SM), ISRJ, 2(5). Retrieved from www.isrj.net/PublishArticles/966.aspx.

Raimes, A. (1983). Techniques in teaching writing. Oxford: Oxford University Press.

Raimes, A. (1991). Out of the woods: Emerging traditions in the teaching of writing. TESOL Quarterly, 25(3), 407-430.

Seligmann, E. R. (2007). Reaching students through synectics: A creative solution. Retrieved from http://www.ellieseligmann.com/essays/synectics_seligmann.pdf.

Silva, T. \& Matsuda, P. K. (Eds.) (2001). On second language writing. Mahwah, New Jersey: Lawrence Erlbaum Associates, Publishers.

Silva, T. \& Matsuda, P. K. (2002). Writing. In Schmitt, N. (Ed.), An introduction to applied linguistics (pp. 251-266). London: Arnold.

Walker, D. E. (2009). Promoting metaphorical thinking through synectics: Developing Deep thinking utilizing abstractions. Retrieved from http://facstaff.bloomu.edu/dwalker/ ConferenceInformation/IUT/Synectics.pdf.

Weaver, W. T. \& Prince, G. M. (1990). Synectics: Its potential for education. The Phi Delta Kappan, 71 (5), 378-388.

Wolfe-Quintero, K., Inagaki, S. \& Kim, H. (1998). Second language development in writing: Measures of fluency, accuracy and complexity. Honolulu: University of Hawai'i Press. 


\section{Appendix A. Synectics lesson plan.}

\begin{tabular}{|c|c|}
\hline Topic & Justice \\
\hline Aims & $\begin{array}{l}\text { Students generate ideas for the writing task through using different types of metaphor in group } \\
\text { interaction }\end{array}$ \\
\hline Duration & 60 minutes \\
\hline Number of Ss & 20 \\
\hline Materials & Computer, projector, dictionaries, and student reflection forms (Appendix F) \\
\hline Activities & $\begin{array}{l}\text { 1. Describing the topic } \\
\text { 2. Creating direct analogies } \\
\text { 3. Describing personal analogies } \\
\text { 4. Identifying compressed conflicts } \\
\text { 5. Creating a new direct analogy } \\
\text { 6. Evaluating } \\
\text { 7. Re-examining the original topic and writing a paragraph about it }\end{array}$ \\
\hline Procedures & 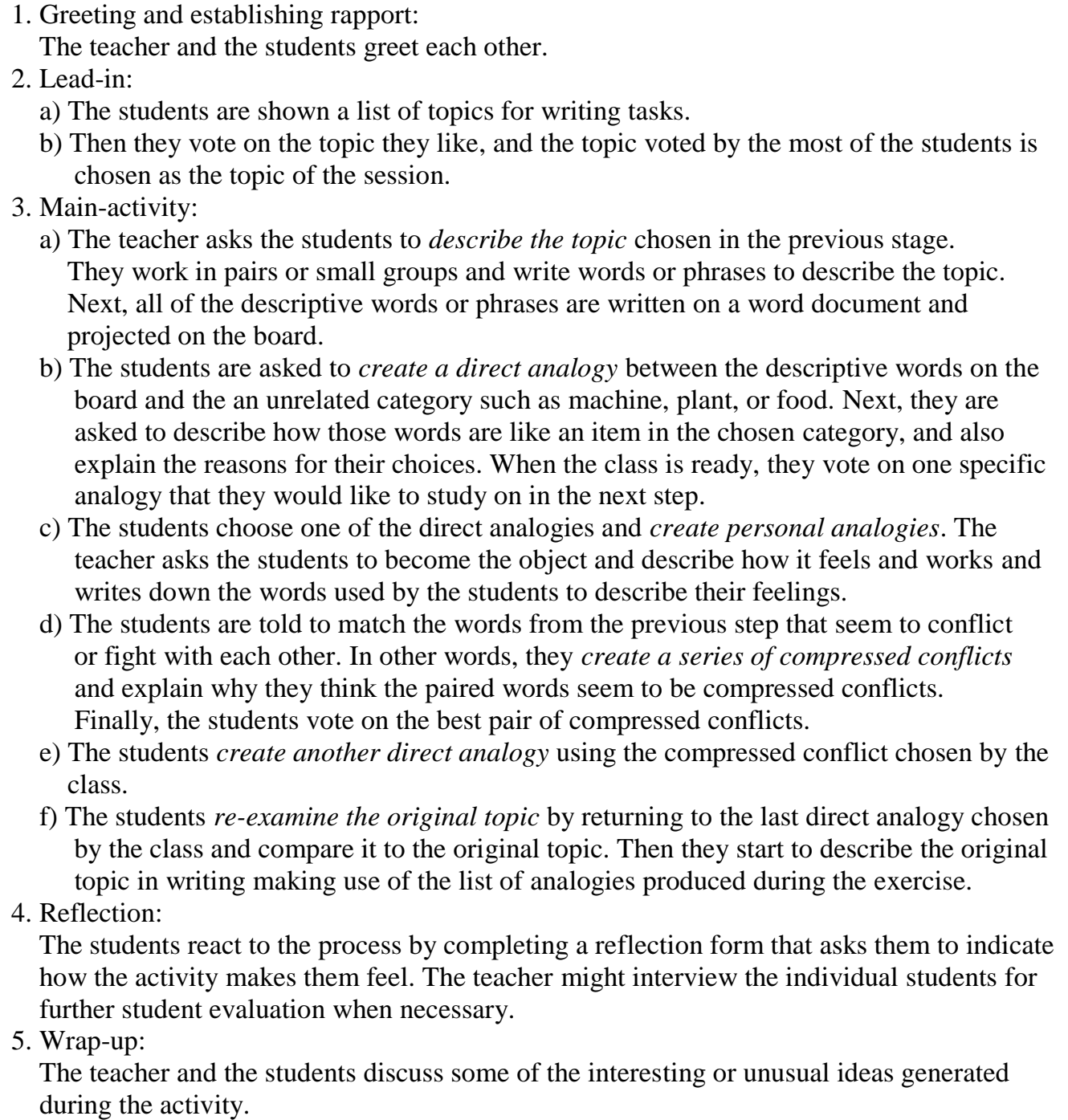 \\
\hline
\end{tabular}


Appendix B. Graphic organizer for synectics sessions*

\begin{tabular}{|c|c|c|c|c|c|}
\hline Definition & Similar & Feels like & Opposite & Similar & Synthesis \\
\hline & & & & & \\
\hline & & & & & \\
\hline & & & & & \\
\hline & & & & & \\
\hline & & & & & \\
\hline & & & & & \\
\hline & & & & & \\
\hline
\end{tabular}

*Taken from http://www.writedesignonline.com/organizers/synectics.html

\section{Copyrights}

Copyright for this article is retained by the author(s), with first publication rights granted to the Journal.

This is an open-access article distributed under the terms and conditions of the Creative Commons Attribution license (CC BY-NC-ND) (http://creativecommons.org/licenses/by-nc-nd/4.0/). 